China's Catholics 


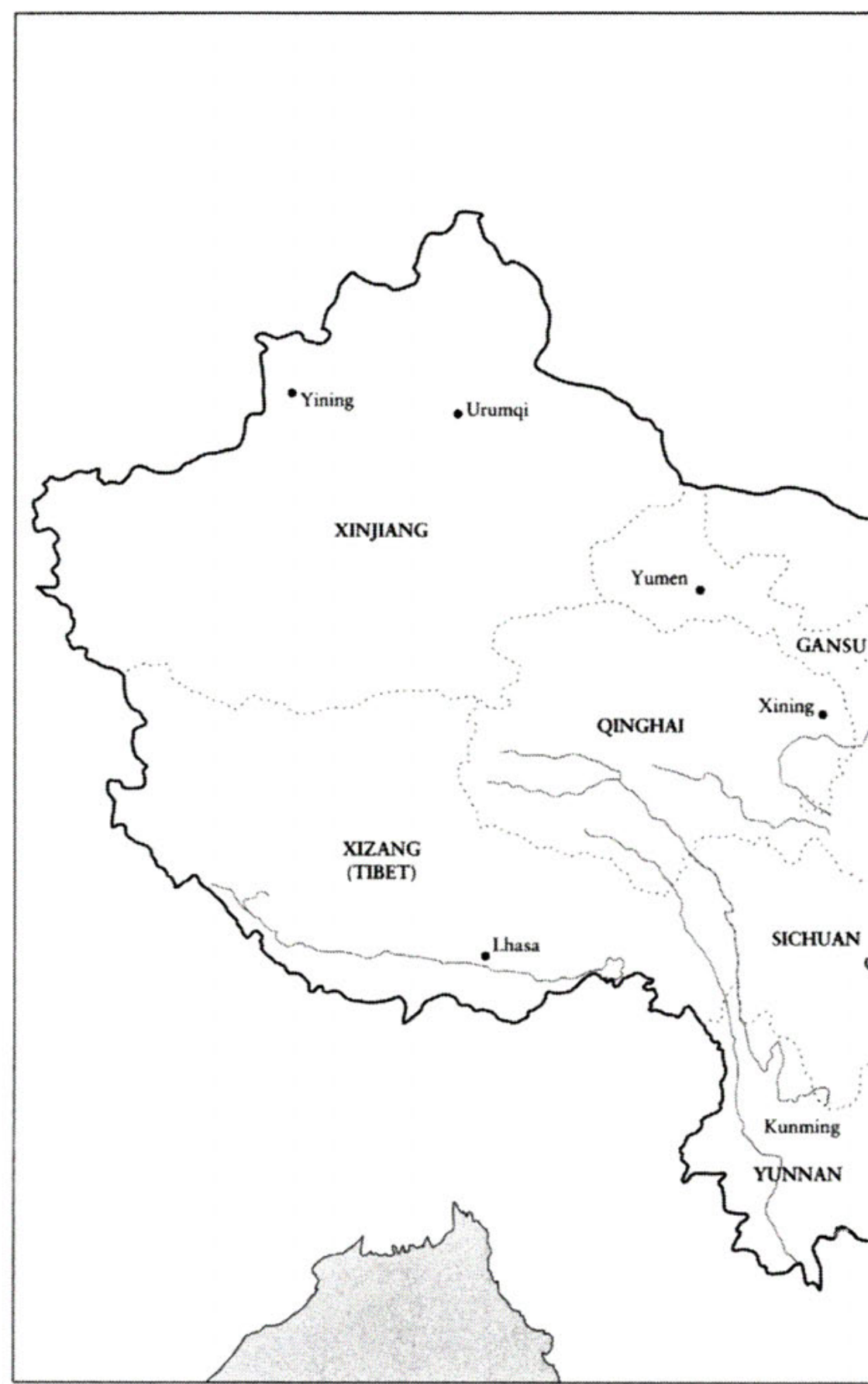

Map r. China: provinces and major cities. 


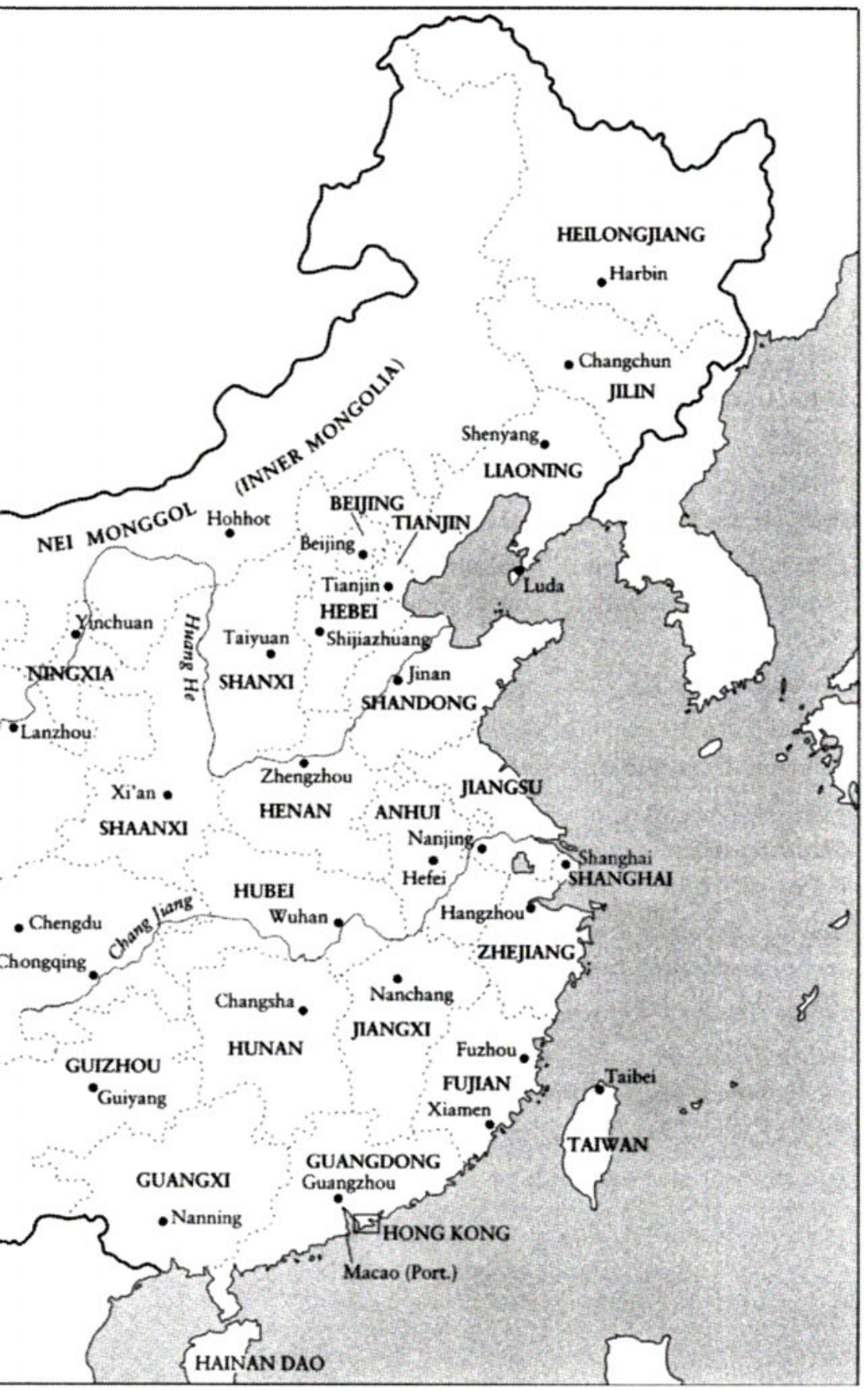


Comparative Studies in Religion and Society

Mark Juergensmeyer, editor

r. Redemptive Encounters: Three Modern Styles in the Hindu Tradition, by Lawrence Babb

2. Saints and Virtues, edited by John Stratton Hawley

3. Utopias in Conflict: Religion and Nationalism in Modern India, by Ainslee T. Embree

4. Mama Lola: A Vodou Priestess in Brooklyn, by Karen McCarthy Brown

5. The New Cold War? Religious Nationalism Confronts the Secular State, by Mark Juergensmeyer

6. Pious Passion: The Emergence of Modern Fundamentalism in the United States and Iran, by Martin Riesebrodt, translated by Don Reneau

7. Devi: Goddess of India, edited by John Stratton Hawley and Donna Marie Wulff

8. Absent Lord: Ascetics and Kings in a Jain Ritual Culture, by Lawrence A. Babb

9. The Challenge of Fundamentalism: Political Islam and the New World Disorder, by Bassam Tibi

ro. Levelling Crowds: Ethno-nationalist Conflicts and Collective Violence in South Asia, by Stanley J. Tambiah

II. The Bridge Betrayed: Religion and Genocide in Bosnia, by Michael A. Sells

I2. China's Catholics: Tragedy and Hope in an Emerging Civil Society, by Richard Madsen 


\section{China's Catholics}

Tragedy and Hope in an

Emerging Civil Society

\section{Richard Madsen}


This book is a print-on-demand volume. It is manufactured using toner in place of ink. Type and images may be less sharp than the same material seen in traditionally printed University of California Press editions.

University of California Press

Berkeley and Los Angeles, California

University of California Press, Ltd.

London, England

(c) 1998 by

The Regents of the University of California

Library of Congress Cataloging-in-Publication Data

Madsen, Richard, r94I-

China's Catholics : tragedy and hope in an emerging civil society / Richard Madsen.

p. $\mathrm{cm}$. - (Comparative studies in religion and society; $\mathrm{I}_{2}$ )

Includes bibliographical references and index.

ISBN 0-5 20-21 326-2 (alk. paper)

r. Catholic Church-China. I. Title.

BXI665.M29 1999

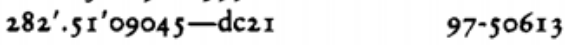

Printed in the United States of America

The paper used in this publication meets the minimum requirements of ANSI/NISO Z39.48-1992 ( R 1997 )

( Permanence of paper ) 